\title{
Representations about emotional reactions to perinatal loss
}

\author{
Elena Markman ${ }^{1, *}$ and Yulya Tushnova ${ }^{2}$ \\ ${ }^{1}$ Russian Christian Humanitarian Academy, Fontanka riv. embankment, 15, St. Petersburg, 191011, \\ Russia \\ ${ }^{2}$ Don State Technical University, Gagarin sq. 1, Rostov- on-Don, 344003, Russia
}

\begin{abstract}
Perinatal loss refers to a traumatic event that has a significant impact on the mental health of a woman. Perinatal loss is a complicated emotional ordeal for both the woman and her family. Women who have lost a child during pregnancy or after childbirth have practically no direct life experience of communicating with an infant, while grief in the context of perinatal loss does not significantly differ in intensity from another type of loss. This article describes the results of a research on the representations regarding emotional reactions while experiencing perinatal loss during pregnancy and after birth. The study involved 84 people, aged 19 to 61 (47\% men). The authors' questionnaire and statistical methods were used (descriptive statistics, Mann Whitney test, Wilcoxon Test, and $\chi^{2}$-test). It was established that the representations about the situations that can be attributed to perinatal loss and types of assistance are different for men and women who have the experience of perinatal loss and those who do not; the differences are observed in the assessments of emotional experiences during the loss of a fetus and the loss of a newborn for men and women who have the experience of perinatal loss, and those who do not; men and women may have differences in assessing emotional experiences in the situation of losing a fetus during pregnancy or losing a newborn. The perspectives of the research are the study of factors influencing the loss and distortion of the image of the physical I for women who have experienced perinatal loss.
\end{abstract}

\section{Introduction}

The loss of a loved one turns the idea of the world upside down, divides life into "before" and "after". The concepts of "grief" and "loss" are often used synonymously. Izard C. defines grief as "a complex structure which consists of fundamental emotions and emotionalcognitive interactions. The psychological cause of grief is affective attachment and the loss of a significant object, and hence the loss of love, security, or a sense of well-being" [1]. By loss, the human experience is meant associated with death; and grief is the feelings, and the suffering of the grieving person and their manifestation. In psychology, the concept of "loss" is understood as the loss of something significant, valuable, something to which the individual has a strong affective attachment, something that contributes to the individual's feeling of the integrity of oneself and the stability of one's existence. Loss can be physical

\footnotetext{
* Corresponding author: Lev195197@gmail.com
} 
and symbolic. Physical loss is the loss of a tangible object, which is obvious and understandable to others. Symbolic loss is the loss of something intangible, but symbolically significant for a person. Perinatal loss is a collective concept that combines the mortality of viable fetuses from the $28^{\text {th }}$ week (since 2012 - from 22 weeks) of pregnancy to the onset of labor for the mother, as well as during childbirth and the mortality of children during the first 168 hours (7 days) of life [2]. The Big Medical Encyclopedia defines the concept of "perinatal loss" as: the situation of miscarriage, abortion, ectopic pregnancy, antenatal and intrapartum fetal death, failure in in vitro fertilization, death of one of the fetuses during multiple pregnancy, death of a newborn child, in some countries the death of an adopted baby, as well as incurable sterility [3]. The perinatal loss remains an important demographic issue of concern in the modern world, and, according to the data for 2018, every fifth Russian family is faced with reproductive or perinatal losses [2, p. 26]

The experience of losing an unborn child or a child who has died a few hours (days) after birth is a depressing loss. The loss of a child becomes a loss of hopes, dreams, and plans for the future of failed parents. Perinatal loss contains two components: on the one hand, there is a physical absence of the fetus (child), and on the other hand, his or her psychological presence remains. The bond between parents and children is not only particularly strong, but is also an integral part of the identity of many parents and children [4].

Perinatal loss, as a traumatic situation, is a sudden, uncontrollable event that has an intense negative impact on the personality. To describe the traumatic event, the metaphor of "personality breakdown", "loss of a part of oneself" or "part of one's personality" is often used. The depth of the disruption of the subsystems and the level of impact of the traumatic event on the personality directly depends on the degree of a person's ability to adapt to a traumatic situation, and on building new emotional connections after the loss [5-7]. A traumatic situation is characterized as a dynamic process "influencing perception; namely, how the vision of the present, past and future changes". A traumatic event divides life "into before and after" [8-10].

An additional precipitating factor is that if the loss occurs on an early stage of pregnancy, funerals or other rituals of mourning are usually not performed and family and friends may not acknowledge the loss, in which case the perinatal loss takes the form of powerless grief and ambiguous loss [11-13].

During pregnancy, especially closer to the last trimester of pregnancy, a woman develops a strong attachment to her unborn child $[14,15]$. Attachment is an integral part of the identity of many parents and children [4], the basis of a positive self-awareness of oneself as a mother, a parent [16]. The emergence of an emotional bond is due to the biological unity between mother and child. Applying J. Bowlby's theory of attachment is important for understanding perinatal loss.

The studies conducted by Russian and foreign authors have shown that perinatal loss can cause many emotional reactions, including psychological stress [3, 17-24]. Reactions to the loss of a child can include temporary disruption of daily functioning, social isolation, the presence of repetitive and intrusive thoughts, feelings of deep sadness, guilt and shame, and an inability to feel sensations and emotions [22-25].

Parental grief is longer than other types of loss. During the first year after the loss, a tendency towards a decrease in psychological stress was noted, while the concern about losing a child accompanies the parents for many years after the loss [4, 26-28]. Describing parental grief, Klass gives the metaphor of "amputation": a vivid feeling of irreparable loss of a part of oneself, to which one can adapt, but which will not grow again [29]. It was noted that at least $20 \%$ of women continue to suffer from clinically significant symptoms one year after their loss $[17,18,25]$. It was shown that perinatal losses adversely affect the psychological well-being of both the mother and the father, other members of their families, and are also associated with post-traumatic stress, depression, anxiety and sleep disorders 
$[20,23,28]$. Moreover, the loss of a child in the perinatal period was defined as a complex and potentially dangerous life experience, which in some cases can further develop into complex grief reactions, characterized by more devastating, widespread or stable symptoms than ordinary grief.

Despite the recognition by society that perinatal loss can lead to significant consequences for the mental health of women, the majority of women do not receive emotional and psychological support [21].

The scientific literature does not dispute the importance of experiencing certain emotions that play a central role in overcoming perinatal loss, such as guilt ("it was my fault") and shame, loss of self-esteem ("other women have managed to give birth to healthy babies") and other emotional reactions in the early stages of the mourning process, which is an important predictor of pathological grief reactions [3, 20, 22]. However, there is a definite lack of research on other emotional reactions to perinatal loss. In the available literature, the authors found the studies related to the study of various factors associated with the intensity of grief for women after pregnancy loss and neonatal death [4, 30, 31, et al.]. Most of these studies examined individual, interpersonal, social, or systemic factors. The concepts of emotional reactions while experiencing perinatal loss during pregnancy and while experiencing perinatal loss after birth have not been studied.

\section{Materials and Methods}

The study involved 84 people, aged 19 to 61 , of which 57\% were women $(M=34)$, and 19\% were men $(M=39)$. Among them, there are: residents of the city of St. Petersburg $-55 \%$; residents of the Leningrad region $-12 \%$; residents of other regions of Russia $-20 \%$; living in other countries $-13 \%$.

$67 \%$ of respondents have higher education, $23 \%$ - two or more higher education; $2 \%-$ an academic degree; 4\% - incomplete higher education; $2 \%$ - secondary vocational education; $1 \%$ of the respondents have incomplete secondary and secondary education, respectively. $52 \%$ of the respondents are married; $19 \%$ are divorced; $16 \%$ are not married; $13 \%$ are in partnerships (unregistered marriage). Having children $-62 \%$, without children $33 \%$, planning children $-5 \% .23 \%$ of the respondents had the experience of perinatal loss.

Methodological tools are presented by the authors' questionnaire (https://docs.google.com/forms/d/1DjJ9SR-xCNMt4-J-

rbg05ovPqD3b5Js6WNN1yxNWntQ/edit), statistical methods (descriptive statistics, Mann Whitney U test, Wilcoxon Test, $\chi^{2}$-test). The reliability of the results was ensured by the anonymity of the survey and sufficient motivation of the respondents. Before the study, a discussion was held with the respondents to explain the goals and procedure of the study.

The questionnaire was compiled according to the methodology and methods of sociological research. The questionnaire consisted of 17 questions, divided into the following blocks.

The first block consists of 5 direct semi-closed questions, the content of which reveals: the situations related to perinatal losses; the relation to perinatal loss, and the type of coping behavior.

The second block contains questions aimed at clarifying emotional behavior and its intensity during perinatal loss. To eliminate the effect of psychological rigidity, the block provides for "distracting questions".

The third block consists of semi-closed questions, clarifies the attitude towards types of assistance for women who experienced perinatal loss; the need to inform the family, close and social environment about perinatal loss; the attitude of society towards the women who underwent perinatal loss. 
The fourth block - socio-demographic characteristics; open-ended questions. One question "personal experience of perinatal loss" has a closed answer: "Yes" or "No".

The questions of the content block of the questionnaire are composed of items from 1 to 10. In this study, the questions of the second block of the questionnaire were analyzed.

The following assumptions were tested: (1) representations about the situations that can be attributed to perinatal loss, and the types of assistance may be different for men and women who experienced perinatal loss, and those who did not; (2) there may be differences in the assessments of emotional experiences during the loss of a fetus and the loss of a newborn for men and women who have the experience of perinatal loss and those who do not; (3) men and women can have differences in assessing emotional experiences in the situation of losing a fetus during pregnancy and losing a newborn.

\section{Results}

The analysis regarding the representations about situations that can be attributed to perinatal loss shows that they are distributed unequally in the sample, as a whole $\left(\chi^{2}\right.$-criterion for comparing theoretical and empirical distributions). The situations corresponding to perinatal loss are recognized to a greater extent to be the death of a newborn, and stillbirth (Table 1), abortion at the request of a woman in the representations of the surveyed men and women is the least consistent with the situation of perinatal loss.

Table 1. Comparison of the theoretical and empirical distribution of representations about the situation of perinatal loss.

\begin{tabular}{|l|c|c|c|c|}
\hline \multicolumn{1}{|c|}{$\begin{array}{c}\text { Situations of } \\
\text { perinatal loss }\end{array}$} & $\begin{array}{c}\text { Corresponds to the } \\
\text { situation of perinatal } \\
\text { loss (expected n=42) }\end{array}$ & $\begin{array}{c}\text { Does not correspond to } \\
\text { the situation of perinatal } \\
\text { loss (expected n=n) }\end{array}$ & $\boldsymbol{\chi}^{\mathbf{2}}$ & $\mathbf{p}$ \\
\hline $\begin{array}{l}\text { Abortion at the } \\
\text { request of the woman }\end{array}$ & 28 & 56 & 9.333 & 0.002 \\
\hline $\begin{array}{l}\text { Spontaneous } \\
\text { abortion (early } \\
\text { miscarriage) }\end{array}$ & 56 & 28 & 9.333 & 0.002 \\
\hline $\begin{array}{l}\text { Abortion for medical } \\
\text { reasons }\end{array}$ & 56 & 28 & 9.333 & 0.002 \\
\hline $\begin{array}{l}\text { Spontaneous } \\
\text { abortion (late } \\
\text { miscarriage) }\end{array}$ & 67 & 17 & 29.762 & 0.000 \\
\hline Stillbirth & 72 & 12 & 42.857 & 0.000 \\
\hline Death of a newborn & 77 & 7 & 58.333 & 0.000 \\
\hline $\begin{array}{l}\text { Death of one fetus in } \\
\text { multiple pregnancy }\end{array}$ & 61 & 23 & 17.190 & 0.000 \\
\hline
\end{tabular}

It was found that the representations about the situations that can be attributed to perinatal loss and types of assistance can be different for men and women who had the experience of perinatal loss and those who did not $\left(\chi^{2}\right.$-criterion for comparing several empirical distributions). There are different ideas about abortion for medical reasons and the death of a fetus in multiple pregnancy (Table 2). 
Table 2. Representation about the situation of perinatal loss for men and women who had the experience of perinatal loss and those who did not.

\begin{tabular}{|l|c|c|c|c|}
\hline Situations of perinatal loss & $\begin{array}{c}\text { Experience of } \\
\text { perinatal loss (\%) }\end{array}$ & $\begin{array}{c}\text { Lack of experience of } \\
\text { perinatal loss (\%) }\end{array}$ & $\chi^{\mathbf{2}}$ & $\mathbf{p}$ \\
\hline $\begin{array}{l}\text { Abortion at the request of the } \\
\text { woman }\end{array}$ & 29.2 & 35 & 0.263 & 0.608 \\
\hline $\begin{array}{l}\text { Spontaneous abortion (early } \\
\text { miscarriage) }\end{array}$ & 75 & 63.3 & 1.05 & 0.306 \\
\hline Abortion for medical reasons & 87.5 & 58.3 & 6.563 & $0.01^{* *}$ \\
\hline $\begin{array}{l}\text { Spontaneous abortion (late } \\
\text { miscarriage) }\end{array}$ & 91.7 & 75 & 2.95 & 0.086 \\
\hline Stillbirth & 95.8 & 81.7 & 2.81 & 0.094 \\
\hline Death of a newborn & 91.7 & 91.7 & 0.000 & 1 \\
\hline $\begin{array}{l}\text { Death of one fetus in multiple } \\
\text { pregnancy }\end{array}$ & 95.8 & 63.3 & 9.106 & $0.003^{* *}$ \\
\hline
\end{tabular}

Note: ${ }^{* *}$ - significance level $0.01, *$ - significance level 0.05 .

The representations about the types of assistance required for perinatal loss are unevenly distributed ( $\chi^{2}$-criterion for comparing theoretical and empirical distributions), excluding the help of the family and informational support from doctors. The types of assistance involved in the analysis constitute a number of preferences (from greater to lesser), namely, the help of a psychologist and a partner is called significant (Table 3). The lowest frequency weight has the representation that a woman can cope on her own in the situation of perinatal loss.

Table 3. Comparison of the theoretical and empirical distribution of representations about the types of assistance for perinatal loss.

\begin{tabular}{|l|c|c|c|c|}
\hline \multicolumn{1}{|c|}{$\begin{array}{c}\text { Situations of } \\
\text { perinatal loss }\end{array}$} & $\begin{array}{c}\text { Corresponds to the } \\
\text { situation of perinatal } \\
\text { loss (expected n=42) }\end{array}$ & $\begin{array}{c}\text { Does not correspond to } \\
\text { the situation of perinatal } \\
\text { loss (expected n=n) }\end{array}$ & $\boldsymbol{\chi}^{\mathbf{2}}$ & $\mathbf{p}$ \\
\hline Assistance of a partner & 63 & 21 & 21 & 0.000 \\
\hline $\begin{array}{l}\text { Assistance of a } \\
\text { psychologist }\end{array}$ & 69 & 15 & 34.714 & 0.000 \\
\hline Assistance of family & 49 & 35 & 2.333 & 0.127 \\
\hline Assistance of friends & 25 & 59 & 13.762 & 0.000 \\
\hline $\begin{array}{l}\text { Assistance is not } \\
\text { required }\end{array}$ & 4 & 80 & 68.762 & 0.000 \\
\hline $\begin{array}{l}\text { Information support } \\
\text { from doctors }\end{array}$ & 49 & 35 & 2.333 & 0.127 \\
\hline $\begin{array}{l}\text { Addressing to religion, } \\
\text { spiritual practices }\end{array}$ & 17 & 67 & 29.762 & 0.000 \\
\hline Medical assistance & 30 & 54 & 6.857 & 0.009 \\
\hline
\end{tabular}

It was found that there are significant differences in the representations about informational support from doctors for men and women who had the experience of perinatal loss and those who did not ( $\chi^{2}$-criterion for comparing several empirical distributions). There are different representations regarding informational support from doctors (Table 4). The representations about the need for other types of assistance do not differ depending on the factor of the experience of perinatal loss and are distributed according to the data in Table 3. 
Table 4. Representations about the types of assistance for perinatal loss for men and women who had the experience of perinatal loss and those who did not.

\begin{tabular}{|l|c|c|c|c|}
\hline Situations of perinatal loss & $\begin{array}{c}\text { Experience of } \\
\text { perinatal loss (\%) }\end{array}$ & $\begin{array}{c}\text { Lack of experience of } \\
\text { perinatal loss (\%) }\end{array}$ & $\boldsymbol{\chi}^{\mathbf{2}}$ & $\mathbf{p}$ \\
\hline Assistance of a partner & 75 & 75 & 0.000 & 1 \\
\hline Assistance of a psychologist & 91.7 & 78.3 & 2.078 & 0.149 \\
\hline Assistance of family & 58.3 & 58.3 & 0.000 & 1 \\
\hline Assistance of friends & 37.5 & 26.7 & 0.962 & 0.327 \\
\hline Assistance is not required & 4.2 & 5.0 & 0.026 & 0.871 \\
\hline $\begin{array}{l}\text { Information support from } \\
\text { doctors }\end{array}$ & 75 & 51.7 & 3.84 & $0.050^{*}$ \\
\hline $\begin{array}{l}\text { Addressing to religion, } \\
\text { spiritual practices }\end{array}$ & 12.5 & 23.3 & 1.246 & 0.264 \\
\hline Medical assistance & 41.7 & 33.3 & 0.519 & 0.471 \\
\hline
\end{tabular}

Note: ** - significance level $0.01, *$ - significance level 0.05 .

There is a tendency for manifesting differences in some assessments of emotional experiences during fetal loss for men and women who have the experience of perinatal loss and those who do not (Mann Whitney U test). In the case of fetal loss, the assessments of helplessness, sadness, worry, fear, anxiety and loneliness are significantly different for men and women who have the experience of perinatal loss and those who do not (Table 5).

Table 5. Evaluation of emotional experiences during fetal loss for men and women who have the experience of perinatal loss and those who do not.

\begin{tabular}{|l|c|c|c|c|}
\hline $\begin{array}{c}\text { Situations of } \\
\text { perinatal loss }\end{array}$ & $\begin{array}{c}\text { Experience of perinatal } \\
\text { loss (m / SD) }\end{array}$ & $\begin{array}{c}\text { Lack of experience of } \\
\text { perinatal loss (m / SD) }\end{array}$ & $\mathbf{U}$ & $\mathbf{p}$ \\
\hline Helplessness & $4.1 / 1.3$ & $4 / 1.1$ & 513.5 & $0.040^{*}$ \\
\hline Sadness & $4.4 / 0.9$ & $4 / 1.2$ & 486 & $0.020^{*}$ \\
\hline Worry & $3.6 / 1.3$ & $3.5 / 1.2$ & 517.5 & $0.044^{*}$ \\
\hline Fear & $3.6 / 1.3$ & $3.7 / 1.2$ & 504 & $0.032^{*}$ \\
\hline Anxiety & $3.8 / 1.1$ & $3.7 / 1.3$ & 451.5 & $0.007^{* *}$ \\
\hline Loneliness & $3.6 / 1.4$ & $3.1 / 1.2$ & 512 & $0.039^{*}$ \\
\hline
\end{tabular}

Note: ${ }^{* *}$ - significance level $0.01, *$ - significance level 0.05 .

There is a tendency for manifesting differences in some assessments of emotional experiences during the loss of a newborn for men and women who have the experience of perinatal loss and those who do not (Mann Whitney U test). If a newborn is lost, the tension assessments are significantly different (Table 6).

Table 6. Evaluation of emotional experiences during the loss of a newborn for men and women who have the experience of perinatal loss and those who do not.

\begin{tabular}{|c|c|c|c|c|}
\hline $\begin{array}{c}\text { Situations of } \\
\text { perinatal loss }\end{array}$ & $\begin{array}{c}\text { Experience of } \\
\text { perinatal loss (m / SD) }\end{array}$ & $\begin{array}{c}\text { Lack of experience of } \\
\text { perinatal loss (m/ SD) }\end{array}$ & $\mathbf{U}$ & $\mathbf{p}$ \\
\hline Tension & $3.9 / 1.6$ & $3 / 1.9$ & 505.5 & $0.033^{*}$ \\
\hline
\end{tabular}

Note: ${ }^{* *}$ - significance level $0.01, *$ - significance level 0.05 .

It was found that men and women have differences in the assessments of emotional experiences in the situation of losing a fetus during pregnancy and losing a newborn (Wilcoxon Test). All presented emotional experiences have differences, except for calmness and boredom (Table 7). These emotional experiences both in the situation of the loss of a fetus and a newborn are estimated less than 1. Most of the presented emotions have higher 
values while assessing emotional experiences in the situation of the loss of a newborn. However, estimates of hope, activity and optimism are higher in a situation of fetal loss.

Table 7. Evaluation of emotional experiences when a fetus and a newborn are lost.

\begin{tabular}{|c|c|c|c|c|c|c|}
\hline $\begin{array}{l}\text { Situations of } \\
\text { perinatal loss }\end{array}$ & Loss of fetus & & $\begin{array}{l}\text { Loss of a } \\
\text { newborn }\end{array}$ & & W & $\mathbf{p}$ \\
\hline & $\mathbf{m}$ & SD & $\mathbf{m}$ & SD & & \\
\hline Unhappiness & 4.14 & 1.07 & 4.74 & 0.81 & $\begin{array}{l}-5.1 \\
\end{array}$ & $0.00^{* *}$ \\
\hline Sadness & 4.14 & 1.1 & 4.6 & 0.98 & -4.22 & $0.00^{* *}$ \\
\hline Helplessness & 4.11 & 1.15 & 4.58 & 1 & -3.62 & $0.00^{* * *}$ \\
\hline Depression & 3.27 & 1.35 & 4.45 & 1.11 & -6.15 & $0.00 * *$ \\
\hline Fear & 3.67 & 1.24 & 4.45 & 1.12 & $\begin{array}{l}-5.28 \\
\end{array}$ & $0.00^{* *}$ \\
\hline Despair & 3.82 & 1.24 & 4.44 & 1.20 & -3.97 & $0.00^{* *}$ \\
\hline Worry & 3.62 & 1.25 & 4.32 & 1.19 & -4.31 & $0.00 * *$ \\
\hline Anxiety & 3.75 & 1.22 & 4.32 & 1.26 & -3.94 & 0.00 ** \\
\hline Guilt & 3.38 & 1.46 & 4.10 & 1.47 & -4.52 & $0.00^{* *}$ \\
\hline Anger & 3.01 & 1.58 & 3.99 & 1.83 & -5.75 & $0.00^{* *}$ \\
\hline Panic & 2.87 & 1.46 & 3.90 & 1.35 & -5.68 & $0.00^{* *}$ \\
\hline Loneliness & 3.23 & 1.27 & 3.87 & 1.40 & -3.87 & $0.00^{* *}$ \\
\hline Irritation & 2.84 & 1.58 & 3.51 & 1.81 & -4.12 & 0.00 ** \\
\hline Tension & 2.69 & 1.72 & 3.25 & 1.84 & -3.17 & $0.002 * *$ \\
\hline Repentance & 2.31 & 1.35 & 3.08 & 1.70 & -3.57 & $0.00^{* *}$ \\
\hline Pudency & 2.29 & 1.56 & 3.04 & 1.71 & -4.83 & $0.00^{* *}$ \\
\hline $\begin{array}{ll}\text { Proneness } \\
\text { conflict }\end{array}$ & 1.73 & 1.53 & 2.20 & 1.63 & -2.49 & $0.013 * *$ \\
\hline Envy & 1.14 & 1.56 & 1.79 & 1.80 & -4.1 & $0.00^{* *}$ \\
\hline Excitation & 0.89 & 1.21 & 1.33 & 1.53 & -3.19 & $0.001 * *$ \\
\hline Jealousy & 0.7 & 1.24 & 1.19 & 1.54 & -3.57 & $0.00^{* *}$ \\
\hline Activity & 0.61 & 1.06 & 0.56 & 1.24 & -0.93 & 0.353 \\
\hline Hope & 1.07 & 1.31 & 0.55 & 1.02 & -3.89 & $0.00^{* *}$ \\
\hline Boredom & 0.31 & 0.9 & 0.44 & 1.1 & -1.06 & 0.287 \\
\hline Optimism & 0.38 & 0.88 & 0.21 & 0.76 & -2.32 & $0.002 * *$ \\
\hline Calmness & 0.2 & 0.71 & 0.16 & 0.63 & -0.76 & 0.449 \\
\hline
\end{tabular}

Note: ** - significance level $0.01, *$ - significance level 0.05 .

\section{Discussion}

The study found that the situations of perinatal loss are the death of a newborn, stillbirth, fetal loss in multiple pregnancy, spontaneous abortion in the early and late stages, as well as abortion for medical reasons. Abortion at the request of a woman refers to perinatal loss as a part of the sample that is less than the expected theoretical value. The research by E. Markman dedicated to the study of age and gender characteristics of attitudes towards perinatal loss; as well as the peculiarities of society's attitude to various types of perinatal losses, showed that "the overwhelming majority refer to perinatal loss - the death of a newborn after birth. Accordingly, other types of perinatal loss are: stillbirth; death of one of the fetuses during multiple pregnancy; spontaneous abortions on the early and late stages of pregnancy; abortion for medical reasons; and pregnancy loss during IVF may not be recognized as traumatic events that affect a woman who has experienced perinatal loss" [32]. This position is shared by A. Lang, A. Fleiszer and F. Duhamel. In a study of ambiguity and disenfranchised grief after perinatal loss, they showed how couples who experienced perinatal loss struggle and experience distress due to various forms of ambiguity, and also how the minimization of such grief by society deprives them of the right to participate in traditional grieving processes [20]. 
The representations of men and women who have the experience of perinatal loss, and those who do not, about the situations that correspond to the loss, are different. There are various representations about the situations of abortion for medical reasons and fetal death in multiple pregnancy. The respondents with the experience of perinatal loss reliably more relate abortion for medical reasons and fetal loss in multiple pregnancy to the situations of perinatal loss that require special treatment and are accompanied by complex emotional experiences.

The representations about the necessary assistance for perinatal loss are not distributed randomly, excluding the help of the family and informational help from doctors. These categories require additional testing on a larger sample, since in this study, the representations about these types of assistance may be random. The most necessary types of assistance are the help of a psychologist and the help of a partner. Help from friends, medical assistance and turning to religion and spiritual practices are less significant in the case of perinatal loss, according to the respondents. The representations that a woman does not need help with perinatal loss are not supported. Men and women with and without the experience of perinatal loss have different representations about the need for medical care in the situation of perinatal loss. The respondents with a loss experience are more focused on receiving medical assistance when experiencing a loss. The need for social support and the organization of joint medical and psychological assistance to women who have experienced perinatal loss is highlighted in modern research [33, 34].

There are also different assessments of emotional experiences of helplessness, sadness, worry, fear, anxiety and loneliness in a situation of fetal loss for men and women who experienced perinatal loss, and those who did not. Helplessness and sadness have estimates close to the maximum and are more pronounced among respondents with the experience of perinatal loss. Moreover, this group of respondents estimates anxiety, worry and loneliness in a situation of fetal loss higher than men and women who have no experience of perinatal loss. At the same time, respondents without the experience of perinatal loss rate higher the fear that occurs when a fetus is lost. Other emotional reactions when assessing emotional experiences in a situation of fetal loss did not differ in these groups. A study conducted by Verdon deMontigny F. and colleagues showed that after perinatal loss, symptoms decreased significantly over time only for women with living children and for women who were satisfied with the quality of provided medical services. For childless women and those who are unhappy with health services, symptoms of perinatal grief did not change depending on the time that passed after perinatal loss [21]. The need for timely psychological assistance after perinatal loss is also indicated by L.A. Pergamenshchik, E.A. Petrazhitskaya, and I.V. Zavgorodnaya.

The general picture of the distribution of emotional reactions shows that the maximum estimates (more than 4) are assigned to feelings of sadness, feelings of helplessness, despair, the lowest estimates (less than 1) - to optimism, boredom and calmness.

In a situation of losing a newborn, respondents without the experience of perinatal loss estimate tension higher than men and women with the experience of loss. Other emotional reactions when assessing emotional experiences in the situation of losing a newborn did not differ in these groups. In the situation of losing a newborn, there are more emotional experiences with maximum estimates (more than 4) than in the situation of losing a fetus. This includes sadness, helplessness, fear, unhappiness, depression, despair, anxiety, worry, and guilt. And there is a greater number of minimum estimates (less than 1): activity, hope, boredom, optimism, and calmness.

The assessments of the emotional experiences of men and women in the situation of losing a fetus and a newborn also have a number of differences. Emotional reactions of boredom and calmness do not differ, assessments of these experiences indicate that they are not significant, according to the respondents, in case of losing both a fetus and a newborn. 
At the same time, a large class of emotional experiences is different. It is interesting that hope, activity and optimism are estimated higher in a situation of fetal loss, while these are more neutral and positively colored emotions. In a situation of losing a newborn, more negatively colored emotions are estimated higher. They are distributed in the following way, the maximum estimates (more than 4 on a 5-point scale) were given to emotional reactions of unhappiness, sadness, helplessness, depression, fear, despair, anxiety, worry, guilt, anger, and panic.

\section{Conclusions}

The results of the study of the representations about emotional reactions during the experience of perinatal loss allow the authors to draw a number of conclusions:

1. men and women with experience of perinatal loss reliably more relate abortion for medical reasons and fetal loss in multiple pregnancy to situations of perinatal loss, requiring special treatment, and accompanied by complex emotional experiences;

2. the most necessary types of assistance are referred to by the respondents as the help of a psychologist and the help of a partner, while respondents who have the experience of loss are more focused on receiving medical assistance when experiencing a loss;

3 . in the situation of fetal loss, men and women who have the experience of perinatal loss estimate helplessness, sadness, worry, anxiety, and loneliness higher, while respondents without the experience of perinatal loss rate the fear that occurs with the loss of a fetus higher;

4. in a situation of losing a newborn, respondents without the experience of perinatal loss estimate tension higher than men and women with the experience of loss;

5. various assessments of emotional experiences in a situation of losing a fetus are more neutral or positively colored, while in the situation of loss of a newborn, more negatively colored emotions are estimated higher, the highest values are given to the feelings of unhappiness, sadness, helplessness, depression, fear, despair, worry, anxiety, guilt, anger, and panic.

The prospects for the study are to establish the factors of loss and distortion of the image of the physical I for women after perinatal loss. The specific objectives are to compare the self-attitude of women after perinatal loss and the self-attitude of women who have one or more children. It is also significant to study the factors affecting the loss of the image of the physical I and develop diagnostic tools to determine the factors influencing the loss of the image of the physical I and provide practical assistance to women who have experienced perinatal loss.

\section{References}

1. C. Izard, Human Emotions (Boston, MA, Springer, 1977)

2. Demographic Yearbook of Russia. 2019: Statistical collection (Rosstat, Moscow, 2019)

3. I.V. Dobryakov, M.E. Blokh, L.M. Faerberg, Journal of obstetrics and women's disease. 64(3), 4-10 (2015) DOI: 10.17816/JOWD6434-10.

4. S. Rubin, R. Malkinson, Handbook of bereavement research: Consequences, cop ing, and care (American Psychological Association Press, Washington, D.C., 2001) https://www.researchgate.net/publication/285862822_Parental_response_to_child_loss _across_the_life_cycle_Clinical_and_research_perspectives

5. O. van der Hart, E.R.S. Nijenhuis, K. Steele, The Haunted Self. Structural Dissociation and the Treatment of Chronic Traumatization (W.W.Norton, New York, 2006) 
https://www.researchgate.net/publication/46681133_The_Haunted_Self_Structural_Di ssociation_and_the_Treatment_of_Chronic_Traumatization

6. A.T. Beck, A. Freeman, D.D. Davis, Cognitive Therapy of Personality Disorders (Pbl. The Guilford Press, NY, 2004)

7. M.A. Padun, N.V. Tarabrina, Psikhologicheskii Zhurnal 25(5), 5-15 (2004) https://www.researchgate.net/publication/288592267_Cognitive-

personal_aspects_of_posttraumatic_stress'_experience

8. N.V. Tarabrina, N.E. Kharlamenkova, Yu.V. Bykhovets et al., Psikhologicheskii Zhurnal 37(6), 94-108

https://www.researchgate.net/publication/314434667_Post-

traumatic_stress_and_the_traumatic_events_in_different_periods_of_adulthood

9. N.V. Tarabrina, Psikhologicheskii Zhurnal 33(6), 20-33 (2012) https://arxiv.gaugn.ru/s0205-95920000616-4-1-ru-200/

10. M.A. Padun, A.V. Kotelnikova, Mental trauma and the picture of the world: Theory, empyria, practice (Cogito-Center Publishing House, Moscow, 2012) https://elibrary.ru/item.asp?id=19135345

11. I. Leon, Glob. libr. women's med (2008) DOI 10.3843/GLOWM.10418

12. K.J. Doka, Disenfranchised grief: Recognizing hidden sorrow (Lexington Books, Lexington, MA, 1989)

13. P. Boss, Journal of Marriage and Family 66(3), 551-566 (2004) doi.org/10.1111/j.00222445.2004.00037.x.

14. I.V. Dobryakov, Perinatal psychology (Pbl Peter, St. Petersburg, 2010) https://search.rsl.ru/ru/record/01004411943

15. J. Bowlby, Attachment. Attachment and loss (Pbl. Basic Books, New York, 1969)

16. J. Bowlby, Attachment and loss: Loss, sadness and depression (Pbl Basic Books, New York, 1980)

17. L.A. Pergamenchik, E.A. Petrazhitskaya, Journal of the Belarusian State University. Philosophy. Psychology 1, 77-84 (2020) https://elibrary.ru/item.asp?id=42417059

18. L.A. Pergamenshchik, N.G. Novak, Social Psychology and Society 6(4), 161-169 (2015) DOI: $10.17759 /$ sps.2015060412

19. P. Hughes, S. Riches, Curr Opin Obstet Gynecol. 15(2), 107-11 (2003) DOI: 10.1097/01.gco.0000063548.93768.17

20. A. Lang, A. Fleiszer, F. Duhamel, OMEGA-Journal of Death and Dying 63(2), 183-196 (2011)

https://www.researchgate.net/publication/51572469_Perinatal_Loss_and_Parental_Gri ef_The_Challenge_of_Ambiguity_and_Disenfranchised_Grief

21. F. De Montigny, C. Verdon, S. Meunier et al., Archives of women's mental health 20(5), 655-662 (2017) https://doi.org/10.1007/s00737-017-0742-9

22. A.S. Vakhrusheva, International Research Journal 11-3(18), 63-65 (2013) https://cyberleninka.ru/article/n/vzaimosvyaz-emotsionalno-lichnostnyh-harakteristiks-osobennostyami-perezhivaniya-utraty-u-lits-zrelogo-vozrasta

23. O.G. Poluektova, Bulletin of New Medical Technologies 1, 151-154 (2013) https://cyberleninka.ru/article/n/travma-poteri-rebenka

24. I.V. Zavgorodnaya, Clinical and medical psychology: research, training, practice: electronic scientific journal 5.2(16) (2017) 
25. H. Volgsten, C. Jansson, A. Svanberg, Midwifery 64, 23-28 (2018) https://doi.org/10.1016/j.midw.2018.05.003

26. R. Malkinson, L. Bar-Tuv, Death Studies 23(6), 413-431 (1999)

27. S.S. Rubin, Death studies 23(8), 681-714 https://doi.org/10.1080/074811899200731

28. W. Fish, Parental loss of a child (Ill: Research Press, Champaign, 1986)

29. D. Klass, Parental grief: Solace and resolution (Springer, New York, 1988)

30. J. Cacciatore, J. Frøen, M. Killian, J. Mental Health Couns. 35(4), 342-359 (2013) DOI: 10.17744/mehc.35.4.15427g822442h11m

31. P. Barr, Psychol Psychother Theory Res Pract 77(4), 493-510 (2004)

32. E.V. Markman, Journal "Modern Science: Actual Problems of Theory and Practice." Series "Cognition" 2, 65-72 (2021) DOI 10.37882/2500-3682.2021.02.17

33. D. Pollock, E. Pearson, M. Cooper et al., Midwifery 93, 102884 (2021) DOI: 10.1016/j.midw.2020.102884/

34. E.L. Poleshuck, J. Woods, American Psychologist 69(4), 344-354 (2014) DOI: $10.1037 / \mathrm{a} 0036044$. 